\title{
Marion Steven and the Logie Collection
}

\author{
ROSWYN WILTSHIRE
}

\begin{abstract}
Marion Kerr Steven (1912-1999), founder of the James Logie Memorial Collection at the University of Canterbury, has been a significant and yet elusive figure in the university's history. A recent oral history project in the Department of Classics has built up a vivid impression of Steven's character and personal influence on her students. Prior to this, Steven's travel diary from 30 November 1958 to 13 July 1959 was donated to the Logie Collection and transcribed in 2017. This article, resulting from research in relation to the transcription, situates Steven in context as a woman in the then male-dominated academic world, and explores her role in reshaping classics as a discipline at the University of Canterbury. The diary records her journeys to London, Rome, and various sites across Greece as she conducted research for teaching purposes, scouted out new objects for the Collection, and participated in meetings of academic organisations. While the period was perceived by many in the field as a time of crisis for classics, Steven appears to have instead seized the opportunity to extend the potential of the discipline.
\end{abstract}

\section{Who Was Marion Kerr Steven?}

Marion Steven, like her two brothers, initially followed in her father's footsteps and gained a degree in medicine at the University of Otago (1935), a background that finds its way into her travel diary with use of doctor's shorthand. She was clearly skilled in this field, for she received a scholarship in pathology at London's Middlesex Hospital, only to have it withdrawn upon her arrival in London as there were "no facilities for women." After two more years at Otago she came to Canterbury (1938), majoring this time in German and Latin. Her work in the Classics Department began as a part-time assistant, and in 1947 she became a Junior Lecturer. Steven quickly rose to Lecturer (1949) and Senior Lecturer (1954), before finally attaining the rank of Reader, equivalent to Associate Professor, in 1966. Steven worked with Professor Arthur Dale Trendall (University of Sydney) in 1948. Renowned for his work on ancient Greek pottery from southern Italy, Trendall was one of the connections from which Steven's own reputation grew. It also seems likely that it was at this point that her focus shifted towards ancient material culture rather than the languages she had studied for her degree. It was in 1948, as it happens, that the Chair of Archaeology, held by Trendall, was established at the University of Sydney; until then only a philologically-centred classics, focused on the study of ancient Greek and Latin, had been offered. Steven married James Logie in 1950, the year he became Registrar of Canterbury College. An iambic triameter response from her colleague H. D. Broadhead suggests that the occasion was unexpected, though certainly not unwelcome. ${ }^{2}$ Only six years later, however, Logie died. Steven ensured the survival of his name with the founding of a teaching collection of antiquities the following year.

\section{Steven's Character}

A reader of Steven's travel diary will note her firmly individual yet restrained nature. She was independent, determined, and possessed an iron will, but managed to maintain the anonymity she favoured. ${ }^{3}$ Her determination is readily apparent in the pages of her diary, where we learn of her knack for getting into closed museums. In one instance she persisted in securing a meeting with Dr. Hermione Speier, an archaeologist and the first woman employed at the Vatican museums, having been twice told that Dr. Speier was not there. ${ }^{4}$ While frequently in 
the company of her friends and colleagues, she was travelling alone. Yet rather than standing out, she had a talent for adapting and communicating with people from all walks of life. Although her notes are often terse, we often get glimpses of her personality and the environments she was in. She attended cocktail and dinner parties with academics and visited great names of the field such as Sir John Beazley. When in Rome, she caught a bus to have tea with the renowned Gisela Richter, apparently a very agreeable encounter: "she is a pet," Steven commented. We learn that she used her connection to Trendall to smooth her way to Richter. And the second time she was told that Dr. Speier was unavailable, Steven again used her connection to Trendall. "Decided it was time to play my trump \& produced ADT's card. It was taken away, \& presently I was asked to come in, \& shown into a waiting room- $\&$ soon she appeared." Use of respected connections is hardly a unique tactic, but it was one that Steven might have found particularly useful as a woman and an academic without publications.

Like many, if not most, people of her time, Steven smoked frequently and used this to grease social wheels in many contexts, particularly beyond the academic sphere. She makes particular note of these social interactions; either it was part of her normal routine or something that stood out in her memory. In any case, she used smoking constructively as a way of bridging differences in occupation and social status. Armed with a dictionary and cigarettes she bused across Greece, where she drank coffee with a crowd of Greek men in the Peloponnese, and exchanged cigarettes at the Athenian agora museum with "a bloke selling postcards." Elsewhere she shared a cigarette with museum attendants during a thunderstorm, and on another occasion notes again that she "smoked a cigarette with 3 sailors from the French warship(s) at Phaleron who were sightseeing." She greatly enjoyed a chance encounter with a local in Athens that led to a conversation comparing modern and ancient Greek:

"We went through the months, \& telling the time-it was rather fun, \& he was not really as emotional as the Italians. . . Missed the Acropolis museum because of this, but decided it was worth it."

As these anecdotes indicate, she enjoyed interaction with all sorts of people; this was also true of the academic scene. She did not only go to tea with important classicists, but also sought out interaction with students. An entry regarding "afternoon tea with 3 second-yr classics students who are doing classical archaeology as a special subject-Juliana, Margaret \& Ray," is followed by notes on the female students' recent trip to Greece; these conversations were equally important to her. Ever an attentive and supportive presence among students, Steven also attended student union meetings in London, and even joined a student march, protesting Apartheid in South African universities:

"Protest march: Marble Arch (via Park Lane, Piccadilly, Haymarket) to Trafalgar Square. Probably as close as I shall ever get to a Park Lane flat or the Dorchesterbehind a banner reading: FREE THOUGHT IS COLOURLESS."

With her versatile social skills Steven blended in rather than projecting a persona; she was not like Jane Harrison, the brilliant, flamboyant and well-known Cambridge classicist from an earlier generation. Nevertheless, to understand the circumstances in which Marion Steven was working it is important to explore the history of women with similar careers.

\section{Women (and Marion Steven) in Academia}

In the last two decades there have been efforts to write women back into the history of Archaeology. ${ }^{5}$ Not all of these women are classical archaeologists, but in order to have a range of women for the sake of comparison, it has been necessary to look beyond strict disciplinary 
borders and beyond national borders. With Canterbury College, and indeed the city of Christchurch itself, inspired by an Oxford model, the situation of English scholars will most closely reflect the circumstances in which Steven was educated and working. Indeed, during Steven's tenure she was the only lecturer in the Classics Department who had not received a degree from a British university. ${ }^{6}$ Until the Second World War, exam transcripts were even sent to England for marking, resulting in the tradition of an April graduation ceremony. ${ }^{7}$ While particular circumstances and cultural norms influence the paths and the characters of early women academics, there were commonalities in the expectations of women and the freedoms they had. Margaret Cool Root distinguishes two generations of early women archaeologists: the pioneers, born around the mid-nineteenth century, and a second generation born between 1890 and 1910. Margarita Diaz-Andreu and Marie Louise Stig Sørensen define 1945-1970 as a third distinct period in the discipline. This period apparently saw more women entering the profession, though few reached top positions. "Academic visibility" remained low, but more women, like Steven, were able to have both a career and a marriage. ${ }^{8}$ Steven herself was born only marginally outside the parameters set for the "second generation" but came later to classics. Her career falls into the span of the "third period," beginning as the "second generation" neared retirement.

We tend to think of the twentieth century as an era of gradual progress in gender equality; reality, of course, is more complicated than a neat continuum. Root notes that the second generation of women archaeologists actually enjoyed fewer freedoms than their pioneering predecessors of the first generation as the discipline became increasingly integrated in the academic sphere, and "increasingly hostage to the same sorts of conservatisms that were rampant in older fields such as classics"-and, we may surmise, the liminal classical archaeology. ${ }^{9}$ Women of the second generation had two principal standards to uphold: that they be paragons of lady-like virtue, and that they consistently achieve a higher standard than their male peers in order to be considered equal. This was not the case for women breaking into the discipline when it was a fledgling area of study away from universities, but applied to secondgeneration women when archaeology was subsumed into academia.

In her biography of classical archaeologist Jane Harrison (and her contemporary, Eugénie Sellers Strong), Mary Beard refers to the Girton College requirement that students sit exams on the same schedule as their male peers, even if, like Eugénie, they had not had the same preparation- - "only thus would they be counted equal to men." However, Beard adds that had she been at Cambridge's other women's college, Newnham, Eugénie would "doubtless have been allowed to take an extra year or so to catch up." Standards, then, were not consistent. An anecdote from the same biography offers insight into the behaviour expected of academic women in the Victorian era. An 1877 performance by Newnham College of Sophocles' Electra was cancelled because the college Principal "objected to the bare flesh that was to be on view, not to mention the dubious morality of young ladies playing male parts." However, both Harrison and Sellers did participate in "theatricals," and neither suffered for it. ${ }^{10}$ The standards of the women's colleges were not necessarily those of academia at large. Rather, this may have been a response to a lack of expectations regarding competency and the view that wider society held on feminine propriety: because academic men did not have high expectation of women's capability, female academics believed they had to be perfect in order to prove this incorrect, and had to prove to general society that being in a male-dominated world did not make them improper. The strictness with which these standards were upheld was obviously not consistent in the pioneering age of Harrison and Sellers and may have remained equally variable for subsequent generations. 
It is difficult to fit Steven into this history of strict standards and more liberal actualities. Canterbury was, from its founding in 1873 as a college of the University of New Zealand, more progressive than the English role models it otherwise closely followed: women were allowed full admission, a right that Oxford only granted in 1920 and Cambridge not until 1948. Nevertheless, it is clear that during Steven's career academia in New Zealand was still a vastly male-dominated sphere. The statistics from the period of Steven's fulltime employment (194777) make it obvious how few women were among the academic staff. We might expect a gradual increase when the University experienced an employment boom in the 1960s, but while the male teaching staff and support staff (mostly technicians) both increased in number dramatically, the number of women remained markedly stagnant [Fig. 1]. ${ }^{11}$ Viewing these statistics as percentages, we see that women formed consistently less than 10 percent of the teaching staff [Fig. 2]. Further, the length of tenure for teaching staff tended to be much shorter for women than men. Only just over 50 percent of women hired during Steven's career remained at Canterbury for five or more years, in contrast to 70 percent of the male staff [Fig. 3]. We cannot easily track these women after their employment ended. Did they find positions elsewhere? Did they marry, returning to careers later or not at all? Regardless, it is clear that, like other women archaeologists of the second generation, Steven belonged to a small minority.

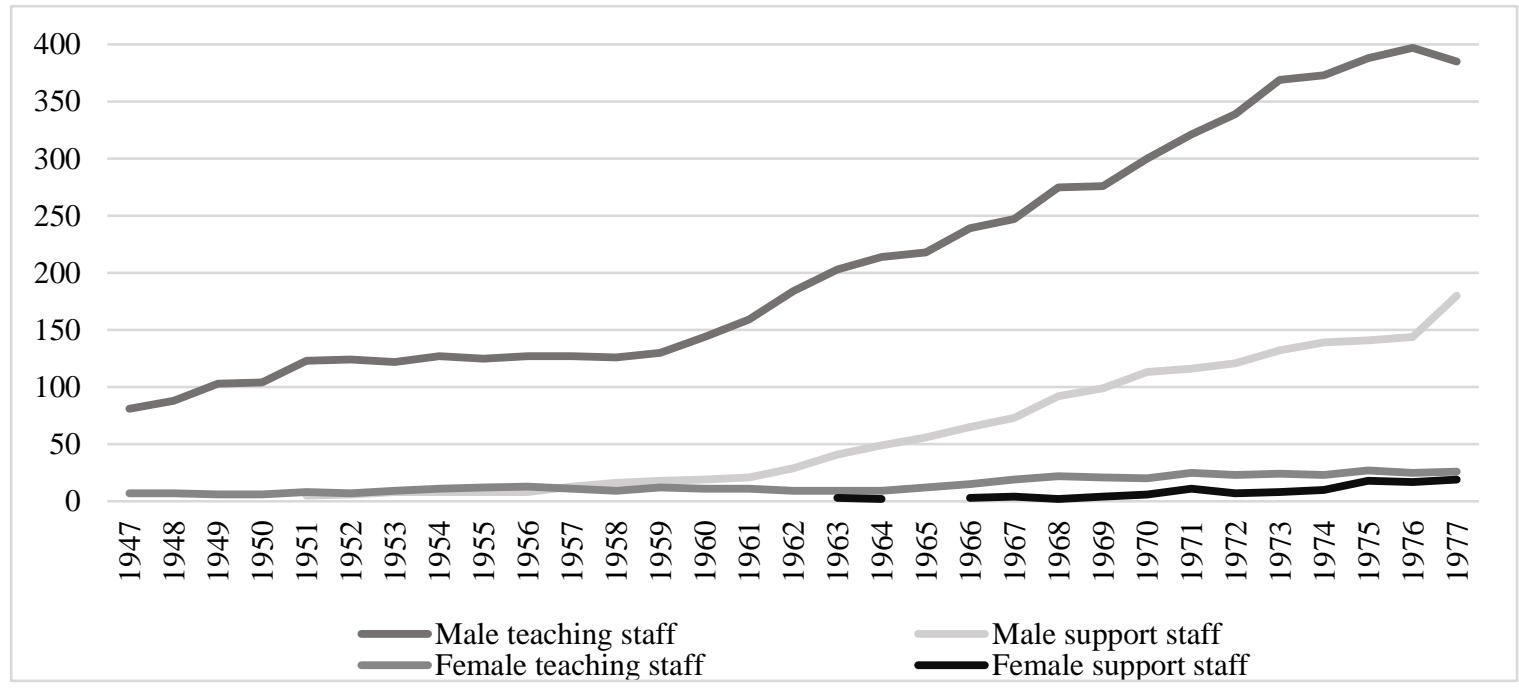

Figure 1. University of Canterbury academic staff, 1947-1977, total numbers

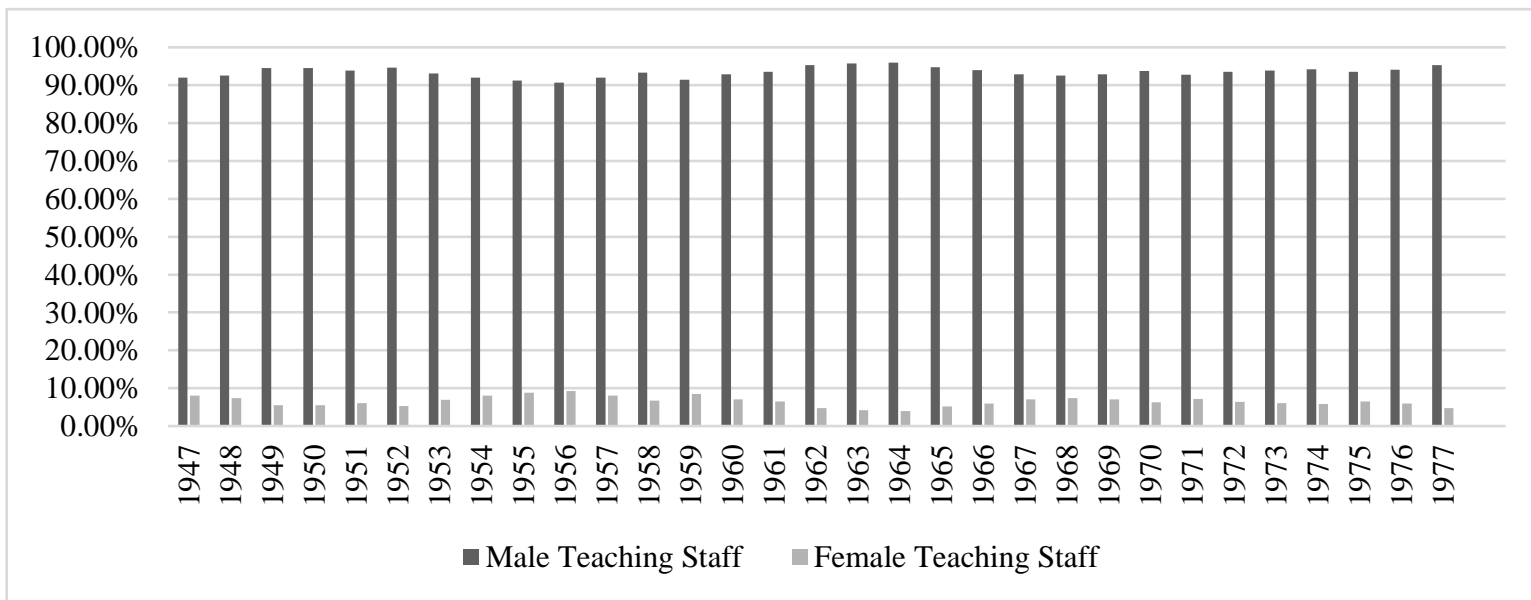


Figure 2. University of Canterbury teaching staff 1947-1977, percentages

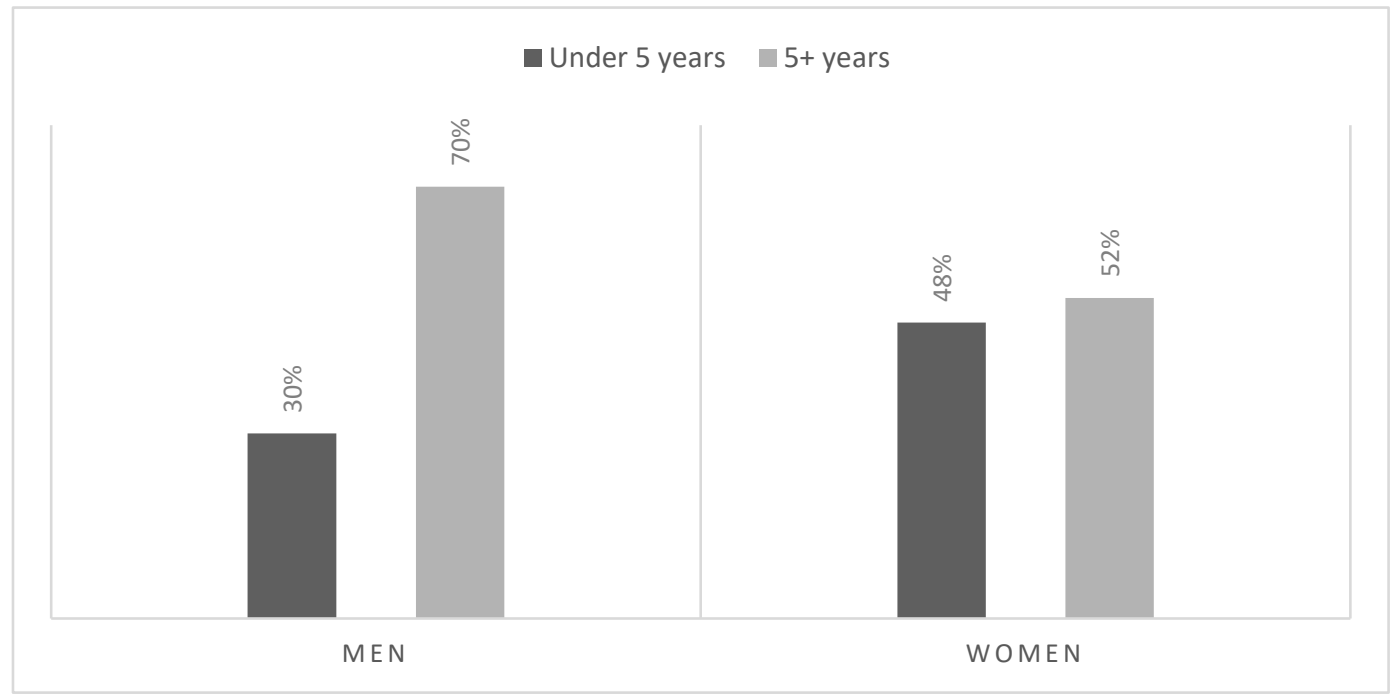

Figure 3. Tenure of University of Canterbury teaching staff hired 1948-1972.

The claim that more women at this time were entering archaeology and academia remains uncertain. Numbers of women increased, but perhaps only in as much as numbers increased overall: the percentage of women in these fields remained low. Sara Champion even reports a drop in women teaching staff at the Department of Egyptology at University College London: until the end of World War Two, women were exactly 50 percent of the teaching staff, but from 1945 until the article's publication in 1998 not a single woman had been hired. Champion added that "a figure of $50 \%$ in any British university seems unattainable, not only in archaeology." 12

Another feature of the "third period"- that marriage and career were not mutually exclusivewas indeed true for Steven. Her marriage was relatively late in life, however, and the preconception was still present, as indicated in the phrasing of Auckland classicist L. W. A. Crawley when he wrote that his colleague Miss Smith "exchanged classics for matrimony."13 (Another exceptional and forthright woman, Miss Smith in fact returned later to professional life, as a lawyer.) Standard expectations of an academic woman's behaviour are perhaps the most difficult to gauge. In her travel diary, Steven does not come across as "ladylike," the requirement of the second generation, but one can hardly expect her private comments to reflect her public face. She did not recount many conversations, and it is therefore difficult to judge her mannerisms. Appearance, however, is a large part of public presentation, and a few hints are dropped in this respect. During her four-day journey to Greece from New Zealand, Steven commented that she was the "only woman in slacks in whole international melange in airport, but not daunted."14 This was obviously something unusual, something that would draw (perhaps negative) attention; certainly something for which a woman would be judged. In fact, the subject of women's attire is even mentioned in the Auckland Classics Department's account of their first hundred years. During the Second World War, Miss Shirley H. S. Smith replaced L. W. A. Crawley, who wrote that she "brought the Department a certain novelty." Miss Smith is introduced with the remark that:

Report had it that she actually wore slacks in the lecture room, and had been known to smoke cigarettes there too. In spite of these very liberated practices of hers, Miss 
Smith's ability in the austere business of teaching Classics was all that could be desired. ${ }^{15}$

Miss Smith was able to succeed in her career, with her skill apparently balancing conservative censure of her habits. ${ }^{16}$ Perhaps, in the manner of the pioneering woman archaeologist Jane Dieulafoy, she was making a statement by wearing "masculine" clothing. ${ }^{17}$ We cannot expect Steven, who was strong minded but did not like to draw attention to herself, to have done the same. Indeed, one of her first diary entries in Athens mentions inquiring about washing nylons, implying that she had switched to skirts and stockings. It may have been her genuine preference, or acquiescence to conform to the general idea of what was "respectable" for a woman. Steven's niece recalls her as being singularly unconcerned about her appearance, but there is suggestion in her diary that at that time she did put effort into her appearance: a comment "no lipstick" when the weather in Rome was too hot implies that normally, or at least frequently, she did use it. ${ }^{18}$ Although Steven cared very little for such things, she apparently did feel obliged to conform to general expectation of a woman's appearance.

Yet there is also the incident of the hat apparently so ugly it was something of a social anathema, admittedly worn only in the presence of friends: "When I put on my ski cap to go round to the pub, J. R. S. said 'Christ!', Robert guffawed, \& Eve was very politely noncomital. ..." Here she chose practicality over fitting in and took pleasure in reporting it. It remains difficult to paint a single portrait, but it would appear that women in academia were to some extent required to fit expectations of feminine propriety imposed by wider society. Conforming to such expectations, in Steven's case, was likely just as much a matter of practicality as the choice to wear slacks when travelling or a hideous ski cap in the cold.

Convenience seems to have also been a determining factor in the use of "Mrs. Logie" as her surname. Names are a very significant part of identity, and the matter was certainly important to Steven. Regarding the foundation of the Logie Collection, she wrote to Canterbury College's rector, Dr. Llewellyn:

The chairman does not mind the gift being made by Miss Steven, but says that the newspapers ought to handle it as Mrs Logie. I don't mind which name people say or write, provided it gets into the official College record as Steven. I have signed both names, and if you'd like to refer to me as Mrs Logie throughout that's fine with meprovided the records are Steven. ${ }^{20}$

She sought no renown and insisted it was not her collection ${ }^{21}$ : perhaps it had to be "Steven" in the records to ensure that the Logie Collection would solely be associated with her husband's memory. Nevertheless, we see elsewhere that she wanted to be known as Miss Steven; in the College calendars she ever remained "Steven." 22 It seems likely that, contrary to prevailing tradition, she maintained her maiden name, only using Mrs. Logie when convenient. A successful classicist and contemporary, Amy Marjorie Dale, published under her maiden name, perhaps to maintain a distinction between herself and her classicist husband (T. B. L. Webster, whom, incidentally, Steven met in 1959). While Steven did not have those concerns, there may be a common thread: a desire to have an identity separate from the traditional role of a married woman.

The feminist scholar Joan Gero has connected the traditional role of women with roles typically assigned to them in archaeology. In contrast to men ("public, visible, physically active, exploratory, dominant and rugged"), there were the "women-at-home-archaeologists," 
relegated to the "base camp laboratory or museum." Such typecasting was "reflecting the prevailing social and political ideology that aims at giving women a passive role in society."23 Root has some concerns with this approach: the tone adopted tends to denigrate the work performed by women, because it was seen as "suitable" for women in the male-dominated hierarchy. The unfortunate side effect of illuminating the problem of gender typecasting in archaeology is the erasure of vital work that women did achieve. After all, what is the point in excavating artefacts if they are not examined properly? The shortcuts in excavation protocol taken by more "treasure"-inclined excavators was a topic of conversation at an academic cocktail party: "one of the troubles was the Wace scheme of digging, i.e. Wace never kept plain fragments, only figured ones, \& Huxley, conforming to the scheme, once discarded a lot of plain fragments of Ephyrean cups." 24 Essentially, the cavalier excavating process resulted in precious evidence being discarded in preference of aesthetically more interesting samples. Painstakingly cataloguing fragments was precisely the sort of work that women were often confined to: it was important work, but as it was neither the initial excavation nor the eventual publication, such work remained invisible. It was certainly the "unheroic," nitpicking examinations that Marion Steven favoured, as evidenced in her travel diary. Some of the most detailed entries are accounts of excavations sites she visited and artistic minutiae on artefacts she saw, such as the direction of deer tails on a vase. ${ }^{25}$ With her discerning eye she carefully selected the first vases of the Collection. Even at its smallest, the Logie Collection soon attracted attention. ${ }^{26}$

In many respects, Steven's career was typical for women classicists of her time, named by Diaz-Andreu and Stig Sørensen the "third period." She was able to have both marriage and career, although hers was an atypical and childless marriage, and while she undertook important work it was of the sort generally overlooked. Steven's experiences recorded in her diary add more nuance to the notion of academic visibility, however. In spite of having never published, she does appear to have enjoyed close connections to very renowned colleagues and was perhaps not entirely invisible among her contemporaries. Although Victorian mores on women's behaviour were no doubt stricter than those of Steven's time, the comparison to Sellers and Harrison reveals some continuity as well as change: women did flout conventional propriety and have successful careers. The question remains as to how many women could do this. Another way in which Steven was typical was the fact that she belonged to a tiny minority. The extent to which her success was the result of her wilful determination or improvement in the culture of academia can only be guessed at if thorough research is ever conducted into the opinions and conduct of her male colleagues.

\section{Establishing the Logie Collection and Building the Future of Classics}

While Steven did acquire and inquire after additions to the Collection on her travels, this was part of a larger goal: expanding the classics curriculum at Canterbury. Her detailing of ancient art and archaeological sites throughout her diary was undoubtedly intended to be used in teaching, and her photographs became lecture slides, still preserved in the Collection. While she had come to the discipline through the ancient languages, it was her experience in classical archaeology that put her in a position to influence the direction of the Classics Department at Canterbury, and it is here that the Logie Collection fits into the narrative.

Steven's raison d'être for founding the Collection was deeply personal: "the purpose of the collection is to do honour to my husband." 27 What she was honouring Logie with was not merely a collection of ancient Greek vases, but a teaching tool responding to the turning tides in social and academic opinion that eventually reshaped the discipline of classics. What began 
largely as a move to reform Latin tuition saw the broadening of the discipline beyond its primarily philological function. The Logie Collection is a part of this widening approach, and in order to understand its significance we must unpick the fabric of society at the time.

The reform of Latin - and with it, classics - was motivated by concerns at secondary school dropout rates, the post-Second World War drive to open tertiary education to a broader spectrum of society, and a decreasing appreciation for the humanities subjects in general and classics, a discipline long perceived as elitist, in particular. The declining status of classics was also evident in New Zealand: statistics show that at Canterbury College, classics did not experience the same expansion as other departments, and when Steven retired in 1977, it was the smallest department in the entire university.

During her 1959 travels, Steven encountered some outspoken anti-classics sentiment, and in an unexpected place: a British Museum lecture on the then "Elgin Marbles." The famed Parthenon sculptures, taken from the acropolis of Athens by the seventh Earl of Elgin, were presumably in storage at the time of Steven's visit; the restoration of damage the Duveen Gallery sustained during the Blitz would only be completed in 1962. It was a place where one might expect to encounter excuses regarding colonial appropriation habits, but not a tirade against ancient Greek art and its study.

Greece has had a kind of superficial popularity, because Greek and Latin, which are quite useless, were regarded as essential for education in the worst period of our education. ${ }^{28}$

Whilst the removal of Latin as an entry requirement for university was a cause Steven supported, this lecturer appeared to despise not only philological classics but also the study of anything Greek or Roman. Regarding the pediment sculptures of the Parthenon, the speaker proclaimed that "very few people of our education would be taken in by this stuff." He also believed the sculptures to have little value in and of themselves, subsequently denigrating the study of Greek art:

As we judge things in the British Museum its [the Parthenon Marbles'] importance lies in the comparison against the Egyptian background.

And indeed, he held the Greeks and Romans in general to be of little import, claiming that "the new science has swept away this Greek and Roman nonsense so that it's like dust in the corner of the room." Steven was astonished by this lecture, and asked herself "can I have heard this correctly?" She had; she later met someone in Athens who had also attended, and they compared notes. These are but some of the comments Steven managed to get down, and examples, we hope, that did not reflect widely held opinion. Nevertheless, the setting for this lecture does suggest that classics and classical archaeology had cause to feel threatened. R. R. Dyer in 1965 asked "is the study of classical antiquity doomed to become in Australasia a remote and irrelevant area of scholarship, rather like Egyptology?"29 The remedy to disfavour for the discipline was not going to be immediate. But it did begin in the late fifties and has proved vital for the discipline's survival and popularity.

The Classical Association, a British society established in 1903, was long dedicated to advancing education in classics. The Association's account of its first century refers to the 1950s as "a kind of Indian summer" before 1960 and the abolition of Latin as entry requirement for Oxford and Cambridge. The chapter dedicated to this subject mentions a "growing disaffection" that "bubbled under the surface" among a minority associated with secondary 
schools, partly concerned with the actual syllabus. ${ }^{30}$ It is clear from Steven's diary that by 1959 this sense of unease was no longer beneath the surface, and not a minority opinion. A passing comment reveals that removing compulsory Latin was already on the books, and at the forefront of debate: "Let us not set our sights too low: perhaps as well that we should teach fewer people and teach them better. (If compuls. Latin removed by unis.)" "31 The Classical Association and another England-based organisation, the Association for the Reform of Latin, arranged a "week-end refresher course" largely dedicated to discussing Latin. The topic was even reported on in the Sunday Times under the caption "Livelier Latin Urged for Schools.",32 Among her notes from the refresher course is the quote "Can we stop defending Latin by reasons which don't hold good!"33

The shift from a purely linguistic focus to the broader discipline of classics was in motion, and Steven was actively aligning with the changing currents. Mingling with the students at University College London, Steven expressed interest in their compulsory ancient history exam. After the weekend course she inquired about Greek for "non-linguistic students," with the response that she "was welcome to visit the Priory school"-a suggestion that there were some reforms in Greek tuition underway in England. ${ }^{34}$ An article she notes down reveals that the Danes had already made the shift to a curriculum centred more on the ancient cultures than language, and her interest in it suggests that she may have been in favour of such changes. ${ }^{35}$

In New Zealand, the Classics Department at Auckland had faced similar discussion a few years earlier, with the abolition of compulsory Latin for a Bachelor's in Law in 1952. This, however, was not linked to a revision of the curriculum. Professor E. M. Blaiklock expressed "an apprehension that the decision of the University would still further weaken the position of Latin in schools." ${ }^{36}$ Indeed, this proved to be correct, with the result that universities experienced a further decline in the number and ability of ancient languages students. A 1965 article on classics in Australia and New Zealand categorised departments based on the available secondary school education in ancient languages. Canterbury fell into the second category, "centres where no Greek is taught in the schools and little Latin," with the result that universities "have been forced to adapt traditional techniques to the needs of their students and to experiment with methods of promoting their discipline." 37 The tone indicates that the change in the curriculum was purely a survival method, but it seems likely that Steven, with her work in classical archaeology, saw the potential to broaden the discipline. The presence of a teaching collection of antiquities helped facilitate changes, providing primary evidence for courses on art and culture, and most importantly, a means to engage students. Grammar does not have broad appeal, but artefacts that were created and used and buried with real people thousands of years ago can capture minds, making the "there and then" as real as the "here and now." The Logie Collection provides a port of entry to the discipline of classics, particularly vital for students in New Zealand, so far from the antiquities they study. On her travels, Steven sought new additions and advice for the Collection, and the notes in her diary make clear that this was supposed to be something not only to be viewed but also to be handled by students.

Spoke to Metcalf (Cambridge St Johns, interested in Byzantine Coins) regarding Roman coins ... for a teaching collection, where you want the coins to be handled, don't buy collector's pieces - the patination of Roman bronze in mint condition can rub off in half an hour (eg. coin moved on table top) - acid in sweat will harm silvereven resting on a card-disc in a cabinet will destroy surface of a type in relief.

Teaching in an engaging, tangible way was her priority, and she helped reshape classics at Canterbury not simply for the sake of the discipline but for the sake of students. The entire

Journal of New Zealand Studies NS32 (2021), 96-107 - https://doi.org/10.26686/jnzs.iNS32.6866

104 
classical studies curriculum offered across New Zealand in NCEA, typically taught in the final two years of secondary school, is one ultimately born of the post-war change in the discipline. While we now take it for granted, the work Steven was doing, often behind-the-scenes, was part of a momentous change that has since shaped the education of generations. ${ }^{38}$

The Logie Collection was founded within this context: as a part of the move away from a purely philological discipline to one that encompasses culture, history, and classical archaeology. It was an effort to prove the value of the field to the public and climb down from the ivory tower. Discussing the difficulties faced by classics departments in Australasia, Dyer highlighted the importance of university antiquity collections, mentioning that of Canterbury as "the most outstanding" (along with Tasmania's). ${ }^{39}$ This critical role of engaging students and the wider public continues today. The establishment of the Teece Museum for the Logie Collection in 2017 is not only a valuable asset for students, but has also been the driving force behind the Classics Department's move back into the city and the public sphere. Since then, the Collection and museum have provided a wealth of opportunities and experiences to students undertaking degrees in a variety of disciplines beyond classics, and the changing exhibitions have drawn tens of thousands of visitors. Thus, Steven's efforts to make classics a discipline accessible to students of all ages, and to bridge the divide between academic and public spheres, were successful and continue to thrive.

Marion Steven herself remains an elusive figure, but her travel diary offers a glimpse of her personality and the world of classics and classical archaeology in the post-World War Two period, a time of changing tides for the discipline, though not for the presence of women within it. Steven is so interesting a figure and a significant role model because she was dedicated to work that often went uncredited. She rose through the ranks of academia to become Reader, the equivalent of Associate Professor, but without ever publishing. She was devoted not to exciting excavations or fame-wining research, but to her students and discipline. She is not only an example of a woman who made it in a man's world, but a reminder that there are many facets to academia, and many equally important roles. Her dedication and foresight gave fruit to the Logie Collection, a pillar of the Classics Department at the University of Canterbury.

Acknowledgements: Thank you to the reviewer for their helpful suggestions; any remaining inadequacies are my own. I also thank the Steven family for their kind permission to publish.

\footnotetext{
${ }^{1}$ A. Holcroft, "Obituary: Marion Kerr Steven," in Chronicle 34 no. 4 (1999): 8-9.

${ }^{2}$ Letter to Steven, 10 May 1950, Logie Collection Archives, uncatalogued.

${ }^{3}$ For further information on Steven's character and influence on students, see N. Looyer, "Academic Legacy: A Life History Through Collective Memory," Oral History in New Zealand 31 (2019): 1-11.

${ }^{4}$ Marion Kerr Steven, travel diary (Logie Collection Archives, uncatalogued), 103 (29 April 1959); 104 (30 April 1959); and 113-44 (12 May 1959).

${ }^{5}$ The anthologies of studies and biographies chiefly used here are G. M. Cohen and M. Sharp Joukowsky, eds., Breaking Ground: Pioneering Women Archaeologists (Ann Arbor: University of Michigan Press, 2006); M. Diaz-Andreu and M. Stig Sørensen, eds., Excavating Women: A History of Women in European Archaeology (London: Routledge, 1998); and C. Claassen, ed., Women in Archaeology (Philadelphia: University of Pennsylvania Press, 1994).

${ }^{6}$ Only two assistant lecturers, both women, of tenure no more than three years had New Zealand degrees. The 12 other staff were graduates of Cambridge, Oxford, London, St Andrews, Nottingham and Southampton; the preference was for Oxbridge. This was typical of New Zealand universities of
}

Journal of New Zealand Studies NS32 (2021), 96-107 - https://doi.org/10.26686/jnzs.iNS32.6866 
the time. See J. Barsby, "Classics at Otago 3: The Manton Period (1949-65)," paper presented at the Australia Society for Classical Studies conference, Auckland, 24 January 2011, 4.

${ }^{7}$ Disagreement occurred with University of New Zealand governance wishing to maintain a British standard and academic staff desiring to mark their own students. W. J. Gardner, E. T. Beardsley, and T. E. Carter, A History of the University of Canterbury, 1873-1973 (Christchurch: University of Canterbury, 1973).

${ }^{8}$ Cohen and Sharp Joukowsky, Breaking Ground, 1; Diaz-Andreu and Stig Sørensen, Excavating Women, 21.

${ }^{9}$ M. Cool Root, "Introduction: Women of the Field, Defining the Gendered Experience," in Cohen and Sharp Joukowsky, Breaking Ground, 23. Classical archaeology can refer not only to fieldwork but also to the study of artefacts, particularly art. Breaking Ground covers a selection of women whose work was in the field; others, such as Jane Harrison and Eugénie Sellers Strong, were also pioneers who considered themselves archaeologists, but they (like Steven) were concerned with examining art, not excavating it.

${ }^{10} \mathrm{M}$. Beard, The Invention of Jane Harrison (Cambridge, Massachusetts: Harvard University Press, 2002) $18,47$.

${ }^{11}$ Statistics have been gathered from university calendars. While they list all tenured staff, they may not reflect full numbers of women teaching. There is one known case of an untenured women teaching courses: Hilary Langer (MSc Hons), taught third-year courses, and later a compulsory fourth-year course in Biometrics in the Botany department, c. 1967-1982. She took two lectures and two labs of three hours each per week, and was paid by the hour, though unpaid for staff and examiners' meetings (Lisa Langer, personal communication, 1 November 2017).

${ }^{12}$ S. Champion, "Women in British Archaeology," in Diaz-Andreu and Stig Sørensen, Excavating Women, 195.

${ }^{13}$ L. W. A. Crawley and W. E. Richardson, Classics in Auckland. (Auckland: Auckland University, 1983), 144.

${ }^{14}$ Steven, travel diary, 20 (19 December 1958).

${ }^{15}$ Crawley and Richardson, Classics in Auckland, 74.

${ }^{16}$ Crawley and Richardson, Classics in Auckland, 74. Miss Smith's career did not, however, continue in the Auckland Classics Department: she left upon marrying in 1944, studied law, and lectured at Victoria University in Wellington from 1958 to 1960 before becoming a practicing lawyer.

${ }^{17}$ Jane Dieulafoy wore masculine clothing "as a symbol of equality with men." E. Gran-Aymerich, "Jane Dieulafoy, 1851-1916," in Cohen and Sharp Joukowsky, Breaking Ground, 38.

${ }^{18}$ J. Cox, "Marion Steven: A Somewhat Eccentric New Zealand Academic," unpublished manuscript, Logie Collection Archives, uncatalogued; Steven, travel diary, 113 (12 May 1959).

${ }^{19}$ Steven, travel diary, 36, (12 January 1959).

${ }^{20}$ Letter to F. J. Llewellyn, 3 July 1957, Logie Collection Archives, uncatalogued.

${ }^{21}$ In a note to Professor Kidd, in response to an ode he wrote her in Latin upon her retirement, she protested his use of "tuae collectionis" (Logie Collection Archives, uncatalogued).

${ }_{22}$ Probate files, 9 August 1950, R22288021, Box 532, Archives New Zealand, Christchurch Regional Office, Christchurch, New Zealand; 11 August 1999, R24315118, Box 21, Archives New Zealand, Christchurch Regional Office, Christchurch, New Zealand.

${ }^{23}$ J. Gero, "Socio-Politics of Archaeology and the Women-at-Home Ideology,"in American Antiquity 50 (1985): 344.

${ }^{24}$ Steven, travel diary, 144 (5 June 1959). Alan John Baynard Wace, 1879-1957, was an English archaeologist who excavated in Alexandria, Corinth Mycenae, Sparta, Thessaly and Troy.

${ }^{25}$ Steven, travel diary, 22-23 (4 December 1958).

${ }^{26}$ In particular, the "Stilt Walker vase," which has been displayed (on loan) at the Getty Museum.

${ }^{27}$ Letter to F. J. Llewellyn, 3 July 1957, Logie Collection Archives, uncatalogued.

${ }^{28}$ This quotation, and the subsequent ones from the same lecture, are from Steven's travel diary, 42 44 (21 January 1959). The lecturer was conducting the lecture "in absence of the colleague who normally does it." 
${ }^{29}$ R. R. Dyer, "Classical Studies in Australia and New Zealand," L'Antiquité Classique 34, no. 2 (1965): 569-70.

${ }^{30}$ M. Forrest, "The Abolition of Compulsory Latin and its Consequences," in The Classical Association: The First Century 1903-2003, ed. C. Stray (Oxford: Oxford University Press, 2003), 4344.

${ }^{31}$ Steven, travel diary, 67 (7 March 1959).

${ }^{32}$ Steven stuck this article in her diary: 65-67 (6-7 March 1959). The Association for the Reform of Latin Teaching was founded in 1913 by W. H. D. Rouse, championing the direct method.

${ }^{33}$ Steven, travel diary, 66 (7 March 1959), quoting C. W. Baty.

${ }^{34}$ Steven, travel diary, 59 (25 February 1959); 67 (7 March 1959).

${ }^{35}$ P. Krarup, "Greek Culture in Danish Schools," Greece and Rome 22, no. 64 (1953): 11-17. Steven noted "Greek course with reading rather than composition" (Steven, travel diary, 31 [26 December 1958]).

${ }^{36}$ Crawley and Richardson, Classics in Auckland, 81.

${ }^{37}$ Dyer, "Classical Studies in Australia and New Zealand," 562.

${ }^{38}$ It may be noted that changes reducing the classics curriculum have recently been proposed. While regrettable, these changes (removing classics as an option in NECA level 1 and removing Latin) have been suggested because very few schools taught level 1 classics in the first place.

${ }^{39}$ Dyer, "Classical Studies in Australia and New Zealand," 566-67. 